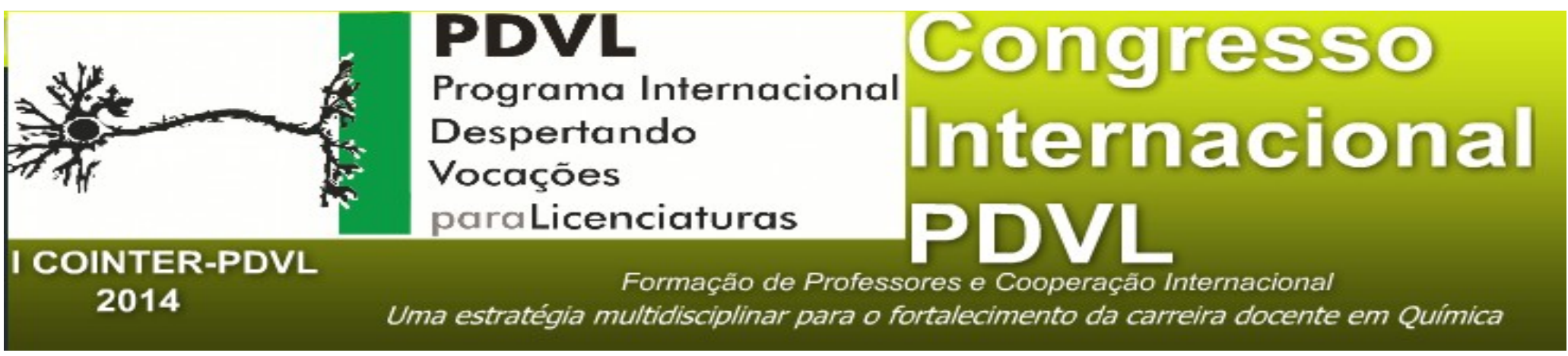

\title{
A EDUCAÇÃO NA ZONA DA MATA SUL DE PERNAMBUCO: APROXIMAÇÕES TEÓRICAS
}

\author{
Apresentação: Pôster \\ Nielson da Silva Bezerra; Maykon Carlos de Oliveira Siqueira. \\ IFPE Campus Barreiros/ nielson.bezerra@barreiros.ifpe.edu.br \\ IFPE Campus Barreiros/ maykonkarlos@hotmail.com
}

\section{Introdução}

Nossa pesquisa nasceu da aproximação entre os cursos superiores de Licenciatura em Química e Tecnólogo em Agroecologia do IFPE campus Barreiros. Nosso objetivo é estudar os processos de construção do saber que emerge das comunidades urbanas de base agroecológica em Barreiros, Tamandaré e Rio Formoso. Temos como referência metodológica a pesquisa qualitativa de cunho participante. Buscaremos acompanhar as ações educativas nas comunidades rurais destes municípios de onde esperamos elencar questões relevantes para a compreensão dos processos que contribuem para a formação educacional nestas comunidades. Nosso interesse é na organização do processo educativo nos espaços rurais, de onde tentamos entender o papel que a educação não formal e formal tem enquanto fenômeno social produzido nestas comunidades. Neste sentido nos referimos à instituição escola, mas também a várias outras instituições que também desejam sistematizar determinados conhecimentos e preceitos morais, tais como organizações políticas, assentados da reforma agrária e demais comunidades rurais. Considerando que uma parte significativa dos estudantes da Licenciatura em Química do IFPE campus Barreiros tem uma origem rural, e que essa identidade encontra-se marcada de preconceitos e estigmas que dificultam o aprendizado destes estudantes, nosso trabalho busca levantar questões relevantes que ajudem a melhorar a qualidade da formação dos licenciados em Química.

A pesquisa encontra-se na fase de levantamento bibliográfico, onde o foco é a investigação do corpus teórico construindo sobre a temática. Nesta fase estamos desenhando um marco conceitual que dê suporte à incursão no campo de estudo. Nossa imersão nas comunidades, escolas e nos estudos científicos da área espera contribuir para a compreensão dos saberes ancestrais aprimorados pelas descobertas da ciência em um processo educativo participativo de 
modo a construir identidades coletivas livres de estigmas, aspecto também necessário ao aprendizado.

\section{Fundamentação teórica}

Nossa compreensão do fenômeno educativo corrobora a compreensão de Arendt (2009a), levada adiante por Brayner (2008), quando afirma:

Penso que não temos o direito de administrar o futuro, de conformar as consciências a vir, ou antecipar as utopias daqueles que nos substituíram e que têm o direito irrecusável de inventar um outro mundo, de pensar o que ainda não foi pensado, em suma, de inovar. (BRAYNER, 2008, p. 55)

Desde modo não concebemos que a Educação possa gerar receitas mágicas infalíveis e que podem ser aplicadas de modo indiscriminado em qualquer realidade social. Por outro lado há uma espaço de aprendizado mútuo, constante e tenso que sobrevive "entre o passado e o futuro" e entre coletividades e ancestralidades que vivem nos mesmos espaços coletivos.

\footnotetext{
Basicamente, estamos sempre educando para o mundo que ou já está fora dos eixos ou para aí caminha, pois é essa a situação humana básica, em que o mundo é criado por mãos mortais e serve de lar aos mortais por tempo limitado. (...) Nossa esperança está pendente sempre do novo que cada geração aporta; precisamente por basearmos nossa esperança apenas nisso, porém, é que tudo destruímos se tentamos controlar os novos de tal modo que nós, os velhos, possamos ditar sua aparência futura. Exatamente em benefício daquilo que é novo e revolucionário em cada criança é que a educação precisa ser conservadora; ela deve preservar essa novidade e introduzi-la como algo novo em um mundo velho, que, por mais revolucionário que possa ser em suas ações, é sempre, do ponto de vista da geração seguinte, obsoleto e rente à destruição. (ARENDT, 2009a, p. 243)
}

Desse modo o processo educativo é sempre específico de seu tempo e de seu lugar, gerando desconfianças e enfrentamentos quando se contradizem ou disputam espaço, como no caso do conhecimento científico e do conhecimento do senso comum.

O lugar do preconceito no processo educativo é ainda pouco estudado, e quando focamos o aprendizado em química e a formação de professores de química, o tema fica ainda mais obscuro. Por outro lado, a identidade "homem rural”, vem sofrendo ataques sociais sútil por uma pretensa inadequação desse perfil diante de nossa contemporaneidade. Essa inadequação, aliás, é bem denunciada nos estudos sobre o preconceito.

Uma das relações dessa ideologia com o preconceito é a de que os homens podem classificar ou outros homens e manipulá-los, uma vez que podem ser pensados como parte de sistemas para os quais cabe designar o seu lugar e 'consertá-los', quando for o caso. Essa 
designação e 'conserto' são possíveis justamente porque o objeto é percebido como dotado de características próprias e independentes da história social e do indivíduo. (CROCHÍK, 2008, p.95)

Identificamos, portanto, um flanco de estudos que precisa ser compreendido para a necessária melhoria da qualidade do ensino na formação de professores de química.

A partir do pressuposto de que a experiência escolar surge de uma indissociável relação consigo mesmo, uma relação com os outros e uma relação com o saber, emerge a questão do desejo como elemento central da relação com o saber. ( LUBURÚ, MAMPRIN, SALVADEGO, 2011, p. 57)

\section{Metodologia}

Nossa pesquisa tem como referência metodológica a pesquisa qualitativa de cunho participante. Buscaremos acompanhar as ações educativas nas comunidades rurais onde o projeto será desenvolvido, de onde esperamos elencar questões relevantes para a compreensão da Educação vivenciada nestes espaços.

A imersão nas comunidades será acompanhada de um estudo teórico investigativo acerca dos seguintes temas: Educação do Campo; Educação e Agroecologia; Educação e Ciência; Educação no meio Rural; Química no meio rural; Educação e campesinato; Formação de Professores de química Os estudos teóricos ocorrerão paralelamente à imersão nas comunidades rurais, de modo que a realidade concreta destas comunidades desafie e seja ao mesmo tempo abordada pelo aporte teórico estudado, de modo que possa abrir caminho para novas formulações teórico-metodológicas.

\section{Resultados Esperados}

Nossa imersão nas comunidades, escolas e nos estudos científicos da área espera contribuir para a compreensão dos saberes ancestrais aprimorados pelas descobertas da Educação em um processo educativo participativo. Reflexão e Ação a serviço das comunidades atendidas e sistematizadas em relatórios e artigos científicos. Esperamos ainda contribuir efetivamente com a aproximação entre a acadêmia e a comunidade circundante, de modo a fortalecer a construção do conhecimento de forma autônoma e colaborativa em ambos os espaços, contribuindo assim para o aprimoramento da Formação de Professores de Química em nossa instituição.

\section{Conclusões}

A construção do Saber é uma característica humana, que desempenha atuações no 
desenvolvimento cognitivo, psicológico e sociológico. As atividades aqui descritas compõem um arco de ações que aspiram contribuir para uma compreensão mais profunda dos processos educativos que ocorrem nas comunidades rurais definidas neste estudo porque entendemos ser essencial para compreensão de nossos estudantes e para a melhoria de sua formação profissional como futuros professores de química. A imersão no aporte teórico tem apontado que o processo educativo se desenvolve de múltiplas formas, basicamente nos espaços formais e não formais de educação.

A experiência de cada indivíduo parece ser fundamental na construção dos saberes eleitos em cada espaço social, e a valorização de cada saber gira em torno da fonte de origem e da forma como este chegou ao indivíduo. A tensão entre espaços formais e não formais de Educação vem produzindo um afastamento mútuo, o que tem contribuindo para visões limitadas de ciência por um lado e de saber útil e legítimo por outro. Acrescenta-se a este cenário uma ideia preconceituosa e estigmatizante dos valores e preceitos morais próprio dos meios rurais, espaço cultural de uma parte significativa de nossos estudantes, futuros professores de química. Diante deste cenário nosso estudo começa a construir bases teóricas para investigar cada um destes modelos no modo como são concretizados em cada espaço, pois acreditamos no fortalecimento mútuo e na construção coletiva da autonomia de cada espaço como ferramenta crucial na melhoria da qualidade da formação profissional no ensino de química.

\section{Bibliografia}

ARENDT, Hannah. Entre o passado e o futuro. Tradução de Mauro W. Barbosa. São Paulo: Perspectiva, 2009.

Forense Universitária, 2010.

BRAYNER, Flávio. Ensaios de crítica pedagógica. Campinas, SP: Autores Associados, 1995.

. Educação e Republicanismo: experimentos arendtianos para uma educação melhor. Brasília: Liber Livro editora, 2008.

CROCHÍK, José Leon. (org.) Perspectivas teóricas acerca do preconceito. São Paulo: Casa do Psicólogo, 2008.

LABURÚ, Carlos Eduardo. MAMPRIN, Maria Imaculada de L. Lagrotta. SALVADEGO, Wanda Neves Cocco. Professor das Ciências Naturais e a Prática de Atividades Experimentais no Ensino Médio: uma análise segundo Charlo. Londrina: Eduel, 2011.

OLIVEIRA, Ariovaldo Umbelino de. A geografia das lutas no campo. São Paulo: Contexto, 2002. 
Instituto Paulo Freire, 2001.

SOUZA, Maria Antônia de. Educação do Campo: propostas pedagógicas do MST. Petrópolis - RJ: Vozes, 2012. 